\title{
Pre-exposure prophylaxis for HIV prevention: Ready for prime time in South Africa?
}

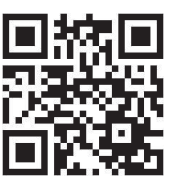

Rates of HIV infection in sub-Saharan Africa remain stubbornly high, ${ }^{[1]}$ despite considerable investment in an array of HIV prevention interventions. The solution to accelerating and sustaining the decline in new infections may be found in the addition of new interventions to the 'tool kit'. These include early antiretroviral (ARV) treatment for prevention, innovative behaviour change methods, 'key population' intervention packages, vaccines and passive immunisation. While all of these have potential, their utility remains unproven.

The most recent breakthrough is pre-exposure prophylaxis (PrEP), where ARVs are administered to someone at risk of sexually acquiring HIV. To date, five trials have demonstrated varying levels of efficacy, four using oral ARVs and one using a vaginal gel or microbicide, with a confirmatory trial underway. ${ }^{[2-6]}$ While efficacy was clearly demonstrated by these trials, many questions remain concerning practical rollout and implementation of PrEP. Guidelines for oral PrEP use have been developed, but operations research is required to validate their effectiveness, ${ }^{[7-10]}$ prompting the World Health Organization to call for demonstration projects. ${ }^{[10]}$

In South Africa (SA), where the HIV epidemic remains the largest in the world, ${ }^{[1]}$ there is a need to reduce new infections. The current South African National Strategic Plan on HIV, sexually transmitted infections and tuberculosis (NSP) specifically calls for the consideration of new modalities for HIV prevention, including PrEP. ${ }^{[11]}$

So, where does PrEP fit within the real-world SA context? Who would get it, and how and where would it be delivered? Will people take it, and how would we ensure that it doesn't further contribute to the problem by generating behavioural disinhibition or resistant strains of HIV? Can we pay for it, and is it cost-effective?

\section{'If you take it, it works':}

\section{The importance of adherence}

The single biggest Achilles heel in all the PrEP studies has been poor levels of adherence. The FemPrEP trial and two arms of the VOICE trial were stopped early owing to futility associated with poor adherence ${ }^{[12-14]}$ Recent results from the remaining active arm of the VOICE trial showed no effect, again due to lack of adherence. ${ }^{[15]}$ In the successful trials, blood and genital secretion drug levels correlated with protection. Over $90 \%$ protection was observed in study patients with high adherence, ${ }^{[16]}$ but the majority of patients throughout the trials did not achieve this level.

The low levels of adherence observed in clinical trials need to be understood, and are currently speculative. In PrEP trials, younger women who are single and at higher risk of HIV have much lower adherence than older, married women, despite intensive adherence counselling and support. Predictably, some prevention research suggests that those who perceive themselves to be at high risk have the best adherence. ${ }^{[17,18]}$ In a clinical trial, advice that the products are either unproven or are placebos may have had an impact on adherence. Less is known about how messages will affect uptake and patterns of use once PrEP is broadly available. Conceptually, contraception is similar in that it is designed to prevent an unwanted event resulting from sexual activity. As with contraception, ${ }^{[19]}$ it would seem that education, proof of efficacy, motivation and recognition of risk drive adherence.
In addition to low efficacy, low adherence could result in the emergence of ARV resistance. There have been few HIV transmission cases in the trials, and modelling has shown that ARV treatment will be the prime generator of ARV resistance, even with widespread PrEP. ${ }^{[20]}$ To avoid resistance, HIV pre-PrEP testing and regular monitoring must be rigorous enough to catch breakthrough infections. Solutions to alleviate daily adherence issues could be found in intermittent dosing, or alternative routes of administration such as injections or a longacting ARV-releasing vaginal ring.

Ability to measure adherence is another sticking point. The trials have clearly indicated that self-reported adherence is not predictive of actual use, as illustrated by plasma and vaginal drug levels. ${ }^{[2-4,12,15]}$ However, in a real-world application of PrEP, laboratory-based adherence measurements may not be practical or cost-effective.

\section{Who gets it?}

PrEP will be most appropriate for individuals at highest HIV risk, but it is not entirely clear how best to reach them. In a concentrated epidemic, where transmissions are centralised to one particular group or groups, delivering focused messages is relatively straightforward. In SA, where the epidemic is generalised and transmissions occur in the broader population, delivering tailored and targeted interventions becomes a major challenge.

Frequently individuals do not identify themselves as at high risk, and some groups at risk, such as young women, are not easy to access through conventional programmes. As research has shown, those who don't see themselves as being at risk have the worst adherence. ${ }^{[12]}$ PrEP is not likely to be the main prevention method of choice for most individuals for extended periods of time, so other options must also be available. For instance, a woman might use PrEP at a time when she feels she is at higher risk, and then stop taking it and choose another prevention option better suited to her changing needs. Furthermore, it is conceivable that the 'worried well' will aggressively seek out this intervention, despite already accessing other effective prevention modalities such as condoms.

In SA, high-risk 'key populations' include adolescent girls and young women, sex workers, men who have sex with men (MSM), discordant couples and truckers, all of whom face various barriers to access including stigma, criminalisation and lack of supportive service delivery infrastructure. ${ }^{[21]}$ If they are to be the focal point for PrEP, it will be imperative to assess how best to introduce PrEP into programmes where these key populations can be accessed and supported.

\section{Delivering PrEP}

If the main recipients of PrEP are 'key populations', service delivery sites must include comprehensive HIV prevention programmes tailored to these groups, with options to suit various prevention needs. The service provision will need to be efficient, sophisticated, reliable and contextually relevant.

PrEP is likely to be complex to deliver. Because certain renal and viral hepatitis conditions are contraindications, oral PrEP has relatively intensive testing and monitoring requirements. Restricting PrEP to being obtained in specialised environments or through general practitioners would mean that fewer people would have access and cost-effectiveness would be reduced. However, broader access within the primary care state sector, already overloaded with multiple programmes, seems unlikely to be an option in the near future. Noting all these constraints, it seems that a PrEP intervention would be best 
integrated into an already successful key population programme embedded within communities where testing and care facilities exist.

In addition to considering the facility and human resource requirements for delivering PrEP, the approach to testing will also be an important element to get right. Frequent testing is necessary to prevent infected people from starting PrEP and to prevent those who contract HIV while on PrEP from developing and possibly transmitting resistant virus, especially as current PrEP medication is used in first-line ARV regimens. Some qualitative studies have indicated that consumers would be willing to test regularly, but these studies were conducted before any products were proven efficacious. ${ }^{[22]}$ At this point it is hard to predict whether responses will translate to real-world application. Reliable home tests may present a solution to the burden of testing, as it may be possible for individuals to test themselves. ${ }^{[23]}$ This should be the topic of second-phase operations research once the field has tested PrEP's programmatic viability under more conservative circumstances.

PrEP use also creates anxiety about potential behavioural disinhibition. So far, data from male circumcision studies, from the PrEP and treatment for prevention trials and from ARV rollout do not support this concern. ${ }^{[24,25]}$ Although some surveys, interviews and focus groups conducted in various user audiences have suggested that users may decide to ignore condoms once PrEP is offered, ${ }^{[25,26]}$ ultimately there will be no way to answer this question until it has been tested in a real-world environment.

\section{Can we foot the bill?}

As with any new technology, the question of affordability, costeffectiveness and competitive budgeting is central to the use of PrEP. In particular there are concerns about whether money will be taken from the treatment budget to pay for PrEP, posing an ethical dilemma in deciding whether healthy individuals should be prioritised over the sick. The ethics of PrEP are important and have been evaluated elsewhere. ${ }^{[27,28]}$ We argue that the discussion should focus on defining the right method mix and how to support it.

Some cost-effectiveness analyses have shown that while PrEP is expensive, there may still be a place for it in terms of impact and reducing the future costs of treatment and HIV management. ${ }^{[29]}$ It is important to note that to date, analyses have been conducted employing some major assumptions about cost structure, delivery mechanisms, population size and efficacy. Now that we have more data from the trials and an opportunity to collect cost information from actual demonstration programmes, we can better assess whether PrEP is worth it.

\section{Conclusions}

While PrEP provides a new technology in the prevention tool kit, it is a complex prevention intervention. Evaluations targeting key populations who are already accessing health programmes must be the next step in understanding its role. In addition, GPs can start prescribing the medication to selected patients. Piloting PrEP in these contexts will allow for cost-effectiveness modelling and produce evidence on which to base future policy and programming decisions.

\section{R Eakle}

London School of Hygiene and Tropical Medicine, UK

\section{W D F Venter \\ H Rees}

Wits Reproductive Health and HIV Institute, Johannesburg, South Africa
1. UNAIDS. UNAIDS World AIDS Day Report 2011. 2011. http://www.unaids.org/en/media/unaids/ contentassets/documents/unaidspublication/2011/JC2216_WorldAIDSday_report_2011_en.pdf (accessed 17 January 2013).

2. Thigpen MC, Kebaabetswe PM, Paxton LA, et al. Antiretroviral preexposure prophylaxis for heterosexual HIV transmission in Botswana. N Engl J Med 2012;367(5):423-434. [http://dx.doi. org/10.1056/NEJMoa1110711]

3. Baeten JM, Donnell D, Ndase P, et al. Antiretroviral prophylaxis for HIV prevention in heterosexual men and women. N Engl J Med 2012;367(5):399-410. [http://dx.doi.org/10.1056/ NEJMoal108524

4. Grant RM, Lama JR, Anderson PL, et al. Preexposure chemoprophylaxis for HIV prevention in men who have sex with men. N Engl J Med 2010;363(27):2587-2599. [http://dx.doi.org/10.1056/ NEJMoa1011205]

5. Abdool Karim Q, Abdool Karim SS, Frohlich JA, et al. Effectiveness and safety of tenofovir gel, an antiretroviral microbicide, for the prevention of HIV infection in women. Science 2010;329(5996):11681174. [http://dx.doi.org/10.1126/science.1193748]

6. Choopanya K, Martin M, Suntharasamai P, et al. Antiretroviral prophylaxis for HIV infection in injecting drug users in Bangkok, Thailand (the Bangkok Tenofovir Study): A randomised, doubleblind, placebo-controlled phase 3 trial. Lancet 2013;381(9883):2083-2090. [http://dx.doi.org/10.1016/ S0140-6736(13)61127-7]

7. Centers for Disease Control. Interim guidance for clinicians considering the use of preexposure penters for Disease Control. Interim guidance for clinicians considering the use of preexposure
prophylaxis for the prevention of HIV infection in heterosexually active adults. MMWR Morb Mortal Wkly Rep 2012;61 (31):586-589. http://www.cdc.gov/mmwr/preview/mmwrhtml/mm6131a2.htm?s_ Wkly Rep 2012;61(31):586-589. http://www.cdc.gov/mmw/preview/mmwrhtml/mm613la2.htm?s id=mm6131a2_w (accessed 17 January 2013).

8. Centers for Disease Control. Interim guidance: Preexposure prophylaxis for the prevention of HIV infection in men who have sex with men. MMWR Morb Mortal Wkly Rep 2011;60(3):65-68. http:// www.cdc.gov/mmwr/preview/mmwrhtml/mm6003al.htm (accessed 17 January 2013).

9. Southern African HIV Clinicians Society Consensus Committee. Southern African guidelines for the safe use of pre-exposure prophylaxis in men who have sex with men who are at risk for HIV infection. Southern African Journal of HIV Medicine 2012;13(2):40-55.

10. World Health Organization. Guidance on oral pre-exposure prophylaxis (PrEP) for serodiscordant couples, men and transgender women who have sex with men at high risk of HIV. 2012. http://www. who.int/hiv/pub/guidance_prep/en/index.html (accessed 17 January 2013).

11. South African National AIDS Council. Strategic Plan on HIV, STIs and TB 2012-2016. 2012. http:// www.sanac.org.za/files/uploaded/NSP\%2027Jan2012\%20Full\%20APPROVED\%2010Feb2012\%20 Web.pdf (accessed 17 January 2013).

12. Van Damme L, Corneli A, Ahmed K, et al. Preexposure prophylaxis for HIV infection among African women. N Engl J Med 2012;367(5):411-422. [http://dx.doi.org/10.1056/NEJMoa 1202614]

13. Microbicides Trial Network. MTN statement on decision to discontinue use of oral tenofovir tablets in VOICE, a major HIV prevention study in women. 2011. http://www.mtnstopshiv.org/node/3619 (accessed 28 March 2013).

14. Microbicides Trial Network. MTN statement on decision to discontinue use of tenofovir gel in VOICE, a major HIV prevention study in women. 2011. http://www.mtnstopshiv.org/node/3909 (accessed 28 March 2013).

15. Marrazzo J, Ramjee G, Palanee T, et al. Pre-exposure prophylaxis for HIV in women: Daily oral tenofovir, oral tenofovir/emtricitabine, or vaginal tenofovir gel in the VOICE study (MTN 003). Presented at HIV Prevention: ARV, Counseling, Contraception, and Condoms. Conference on Retroviruses and Opportunistic Infections, 4 March 2013, Atlanta, Ga. http://www.retroconference. org/2013b/Abstracts/47951.htm (accessed 28 March 2013).

16. Anderson PL, Glidden DV, Liu A, et al. Emtricitabine-tenofovir concentrations and pre-exposure prophylaxis efficacy in men who have sex with men. Sci Transl Med 2012;4(151):151ra125. [http:// dx.doi.org/10.1126/scitranslmed.3004006]

17. Prata N, Morris L, Mazive E, Vahidnia F, Stehr M. Relationship between HIV risk perception and condom use: Evidence from a population-based survey in Mozambique. International Family Planning Perspectives 2006;32(4):192-200. [http://dx.doi.org/10.1363/3219206]

18. Ahmed S, Lutalo T, Wawer M, et al. HIV incidence and sexually transmitted disease prevalence associated with condom use: A population study in Rakai, Uganda. AIDS 2001;15(16):2171-2179. [http://dx.doi.org/10.1097/00002030-200111090-00013]

19. Rosenberg MJ, Waugh MS, Meehan TE. Use and misuse of oral contraceptives: Risk indicators for poor pill taking and discontinuation. Contraception 1995;51(5):283-288. [http://dx.doi.org/10.1016/00107824(95)00074-K]

20. Abbas UL, Hood G, Wetzel AW, Mellors JW. Factors influencing the emergence and spread of HIV drug resistance arising from rollout of antiretroviral pre-exposure prophylaxis (PrEP). PLoS ONE 2011;6:e18165. [http://dx.doi.org/10.1371/journal.pone.0018165]

21. Desmond Tutu HIV Foundation. Key Populations, Key Responses: A Gap Analysis for Key Populations and HIV in South Africa, and Recommendations for the National Strategic Plan for HIV/AIDS, STIs and TB (2012-2016). 2011. http://www.desmondtutuhivfoundation.org.za/documents/KeyPopulations-Key-Solutions-report.pdf (accessed 17 January 2013).

22. Eisulations-Key-Solutions-report.pdf (accessed 17 January 2013). oral and parenteral HIV preexposure prophylaxis among potential user groups: A multinational study.
or oral and parenteral HIV preexposure prophylaxis among potential user group
PLoS ONE 2012;7:e28238. [http://dx.doi.org/10.1371/journal.pone.0028238]

23. Carballo-Diéguez A, Frasca T, Balan I, Ibitoye M, Dolezal C. Use of a rapid HIV home test prevents HIV exposure in a high risk sample of men who have sex with men. AIDS Behav 2012;16(7):17531760. [http://dx.doi.org/10.1007/s10461-012-0274-2]

24. Mattson CL, Campbell RT, Bailey RC, Agot K, Ndinya-Achola JO, Moses S. Risk compensation is not associated with male circumcision in Kisumu, Kenya: A multi-faceted assessment of men enrolled in a randomized controlled trial. PLoS ONE 2008;3:e2443. [http://dx.doi.org/10.1371/journal. pone.0002443]

25. Tripathi A, Whiteside O, Scanlon C, Duffus W. Perceptions and attitudes about pre-exposure prophylaxis (PrEP) among seronegative partners and the potential of sexual disinhibition associated with the use of PrEP. Presented at the XIX International AIDS Conference, 22-27 July 2012, Washington, DC.

26. Smith DK, Toledo L, Smith DJ, Adams MA, Rothenberg R. Attitudes and program preferences of Smith DK, Toledo L, Smith DJ, Adams MA, Rothenberg R. Attitudes and program preferences of
African-American urban young adults about pre-exposure prophylaxis (PrEP). AIDS Educ Prev African-American urban young adults about pre-exposure prophy/

27. Steinbrook R. Preexposure prophylaxis for HIV infection. JAMA 2012;308(9):1-2. [http://dx.doi. Steinbrook R. Preexposure proph
org/10.1001/jama.2012.9885]

28. Jay J, Gostin L. Ethical challenges of preexposure prophylaxis for HIV. JAMA 2012;308(9):1-2. [http:// dx.doi.org/10.1001/2012.jama.10158]

29. Gomez GB, Borquez A, Case KK, Wheelock A, Vassall A, Hankins C. The cost and impact of scaling up pre-exposure prophylaxis for HIV prevention: A systematic review of cost-effectiveness modelling studies. PLoS Med 2013;10(3):e1001401. [http://dx.doi.org/10.1371/journal.pmed.1001401] 